\title{
Methods for Dynamic Characteristics Estimation of Bridge: An Overview
}

\author{
Milind Kosarwal ${ }^{1}$, Sarvesh K Jain ${ }^{2}$ \\ ${ }^{1}$ P.G. Structural Engineering, Madhav Institute of Technology and Science, Gwalior, Madhya Pradesh, India \\ ${ }^{2}$ Professor of the Civil Department, Madhav Institute of Technology and Science, Gwalior, Madhya Pradesh, India
}

\begin{abstract}
Dynamic characteristics of bridge need to be determined for seismic design of bridge. A wide variety of field test and modelling of the bridge have been done to determine the dynamic characteristics of the bridge. This paper intends to present various research works carried out on analytical and experimental methods to evaluate dynamic characteristics of bridges. Paper gives an overview of work published by the researcher and their findings vibration testing, modelling of the bridge, which conducted on different bridges are presented.
\end{abstract}

Keyword: Bridge, Dynamic Characteristic, Finite Element Modelling, Vibration test, Structure Health Monitoring (SHM)

\section{Introduction}

Bridge is an important structure which connects the two different points where the simple road network cannot be established so that which need to be performed throughout the years. Bridge needs to be the study statically and dynamically, to design earthquake Resistance Bridge. So the structural seismic analysis of the bridge requires to determine the dynamic characteristics such as natural frequency, mode shape, and damping ratio [29]. Natural frequency has been recognized as one of the most remarkable characteristic to determination of shear force and damage detection through the vibration based SHM system [32]. Basically, there are two methods used for the calculation of the natural frequency of bridge structure viz. (1) Experimental methods and (2) Analytical methods [35]. In experimental methods the test is performed on the actual structure which requires shaker, sensing system and data acquisition system to measure the dynamic characteristics of the structure. The experimental test is performed to validate the analytical methods, inevitably the result common to natural frequency and mode shapes do not coincide with the expected result of the analytical methods. In analytical methods usually simplified assumptions are considered based on FEM, which makes it highly idealized mathematical model, which may or may not truly represent all the physical aspects of the actual structure. These discrepancies originate from the uncertainties in simplifying the assumption of structural geometry, material, as well as inaccurate boundary conditions. To solve this problem we modify the analytical models from the experimental measurement. This process is called the model updating in structural dynamics. Purpose of model updating is to modify mass, stiffness and damping parameters of mathematical model in order to obtain better harmony between numerical and test result [4]. The objective of this study is to develop a structural health monitoring algorithm by using experimental and analytical methods of calculation for natural frequency of bridge.

\section{Experimental Method}

The experimental techniques are continuously improved in order to study the dynamic characteristics of bridge. This type of test generally requires the sensing system, data acquisition system and shaker for vibration, details of different sensor used for measurement have been provided in text book [8-36]. Primarily three different types of approaches for experimental methods are forced-vibration testing, free-vibration testing and ambient vibration testing are used to obtained dynamic properties of a structures as describe below.

\subsection{Free Vibration Test}

Free vibration test occurs when minor translation is given to the civil structure, it moves away from its original position and gets vibrated. In most of the civil structure energy is lost in the form of friction or heat generation and it causes free vibration decay [22]. Force vibration technique can be successfully applied for civil structure. In experiment study on bridge for free vibration released 60 ton mass form the bridge deck and structure get vibrated [1].

\subsection{Forced-Vibration Test}

Forced vibration test is a calibrated input in the form of sinusoidal concentered force that is applied to produce the frequency of the known value which is controlled by shaker, using the known vibration source. This has several significant advantages over the ambient vibration test [22]. For testing of bridge heavy excitation is produced by the following equipment which are.

- Eccentric rotating mass shaker

- Electro-dynamic shaker

- Electro-hydraulic shaker

In case of forced vibration there are many papers published on bridge using different type of shaker. Salawu and Williams conducted an experiment for comparison of dynamic characteristic of highway Reinforced Concrete Bridge before and after the repair work, it has been found that slightly reduction in natural frequency and the mode 


\section{International Journal of Science and Research (IJSR) \\ ISSN (Online): 2319-7064}

Index Copernicus Value (2015): 78.96 | Impact Factor (2015): 6.391

shape indicates the repair work [31]. Halling et al. conducted an experimental study on forced vibration test on bridge bent and obtained the horizontal frequency and mode shape of structure to compare the dynamic characteristics found by finite element model of bridge [27]. Kim and Stubbs studied on non-destructive crack detection and location of crack methods developed in his paper and the changes on the dynamic characteristic of bridge due to crack is determined by the forced vibration test [20].

\subsection{Ambient Vibration Test}

Ambient vibration test is easily conducted on any type of structure, for the evaluation of dynamic characteristics and analyzing the seismic effect for structure health monitoring (SHM). It is real time recording window for the measurement of vibration caused by the ambient forces. No excitation device is required for ambient forces because ambient force is caused by wind, traffic and ocean wave from nature. During monitoring approach method of testing are important for ambient excitation, tools which are used for the ambient vibration test are seismometers with velocity type transducers, force balanced accelerometers. These equipment measures the oscillation which is obtained from three directions that are longitudinal, transverse, and torsional direction [11]. The ambient vibration methods measures the vibration response while the structure still is service without disturbing the traffic condition. There has been a significant number of research paper published on ambient vibration test for different structure testing.

\section{Analytical Methods}

For natural vibration analysis, a suitable mathematical model and an effective analytical method should be chosen according to the characteristics of geometrical structure, material, load and also according to the degree of freedom [38]. seismic codes are proposing empirical formula based on the common design and construction practice in India for the analytical method in draft Indian standard IS: 1893(part 3 ), natural frequency of the single cantilever pier type of bridge in which the mass is accumulated at the top of the pier, but in case of an ideal cantilever pier model is not possible so mathematical model of bridge is generated on the basis of finite element modelling for the calculation of natural frequency, model the bridge as single degree of freedom system and multi-degree of freedom system for the various natural frequency. The dynamic characteristic of bridge is easily computed and compare the result for model updating by changing the boundary condition and properties of the material for getting better results.

\subsection{Finite Element Modelling}

Finite element modelling of 3D model based on the finite element method for analysis the structure. In this method various small solid elements are defined with the node and mathematical modelling is done for the computation of the structure behavior such as natural frequency, damping ratio, mode shape. FE model updating methods was developed by combining the FE analysis (FEA) with the experimental model analysis (EMA). The aim was to correct the geometrical and physical parameter or boundary condition of initial FE model through a model tuning procedure based on the experimental result such as frequencies and mode shape [16]. Comparison of the analytical and concerned experimental frequencies, it was observed that the FE model has lower natural frequencies because it has insufficient stiffness of an overestimation of mass [12]. FEM also has a wide range of application of different structure to the analysis linear and non- linear behaviors, there is many of research paper on it to use FE modelling such as ( Depiero et al. 2002; Duffield and Hutchinson 2008; Huang et al. 2008; Jaishi et al. 2005; Manasak et al. 2010; Zanjani and Patnaik 2008;).

\section{Ambient Vibration test and Finite Element Modelling of Bridge}

There is heaps of work done on ambient vibration and finite element modelling, but the test started in 1970 and get popular in 1985 in this lot of work is performed in the area of structural dynamic. Some of the paper are discuss the methods for development of the dynamic response of bridge.

Konishi and yamada [1960] The study on the long span suspension bridge is performed for the earthquake response and earthquake resistant design. The dynamic characteristic is analyzed for earthquake resisting design of long span suspension bridge Akashi straits is centered span length is $1300 \mathrm{M}$ side span length $650 \mathrm{M}$ and height of the tower is $200 \mathrm{M}$. The vibration analysis has been done in longitudinal direction and lateral vibration in pier and tower through transmission line. In this model analysis's new mark $\beta$ method was utilized to step-by step iteration. For the response calculation the effect of surround water and seats around the dock with less stiffness dynamic consideration must be exercised. In this paper the direction of motion of structure and earthquake was limited to specific direction, but the earthquake will attack the structure in any way.

Udwadia and Trifunac [1973] Full scale ambient vibration test for structures existed by wind and microtremar ground motion is discussed in four different peaks in this report (1) Compare with higher level vibration, generated test, (2). Compression with earthquake -excited motion (3). Change in ambient vibration response between pre and postearthquake condition (4). Analysis of three dimensional building models. The equipment used is seismometers with velocity type transducers are commonly applied in ambient vibration test, FM- tape recorder analog-digital convertor. Field test is done by two seismometer placed at two different floors for simultaneous recorded data. The registered data are changed over to digital from low Pass filtered to remove on aliasing effects in the computer spectrum. And so the data are next Fourier analyzed. For this test study the linear response of the structure is rather comfortable. The compression of pre and post ambient testing of structure gives valuable information along the overall reduction in structural stiffness caused by dynamic earthquakes.

Gate and smith [1982] Study of 57 bridges by using ambient vibration test and the test result were compared to the computed result from STRUDL model of bridges. Step were involved are field study, Reduction of data, system identification. A comparison between the ambient vibration 


\section{International Journal of Science and Research (IJSR) \\ ISSN (Online): 2319-7064}

Index Copernicus Value (2015): 78.96 | Impact Factor (2015): 6.391

result and higher force level result for two bridges, Meloland rood over crossing in California and rose creek interchange in Nevada is discussed. This helps in the study in the modelling of the bridge for dynamic and static analysis. The field study used the four two second period kinematics model (SS-1) range seismometers; a nimbus instrument ES6C engineering seismographs and Bruel and Kjaer model 7003FM tape recorder is used. The natural frequencies of each bridge were measured in three commissions in addition to the transfers mode shapes. In all the experiments on different bridge one base level was taken so that the mode shape could later be taken out. Reduction of data equipment used a Norland corporation model 3001R programmable wave form analyzer with $3710 \mathrm{R}$ disk drive.an axiom EX801 micro printer, Hewlett pack and 7041A-X-Y platters. The waveform analyzer would read a lot of data from the tape recorded. This information was then examined using a plan written for the analyzer. A Fourier analysis was then done along the data. The ambient result was then compared to a computer analysis of the bridgework. The analysis model was constructed using STRUDL, a multipurpose structural analysis computer program maintained by Mcauto by ST. Louis Missouri. The system identification process involved the fitting of the model natural frequencies and mode shape to the measured natural frequencies and mode shape. When the coefficients matrix could be assembled then a fitting program was utilized to determine the best set of parameter this process was iteratively until the parameter converged. These outcomes indicate that the current dynamic analysis models used for bridges are mostly acceptable. The system identification performed two bridges, turn over the longitudinal superstructure moment of inertia was determined to be between $40 \%$ and $60 \%$ of gross value. The transverse superstructure moment of inertia was determined to be $60 \%$ and $80 \%$ of the gross value. The torsional moment of inertia was determined to be about equal to the gross value.

Toshiro hayashikawa et al. [1988] In his paper dynamic response analysis conducted on the five-span continuous rigid-frame steel bridge (Shibecharic Bridge located in Hokkaido japan) with V-shaped legs standing on two reinforced concrete piers. He found the seismic response of a rigid frame bridge structure is normally dominated by lower and higher mode effect, analysis is performed by applying three different masses matrix consideration such as lumped mass, consistent mass, and continuous mass method for defining the dynamic characteristic in plan vibrating rigidframe bridge is given and also square-root-of-sum-of-square (SRSS) and complete quadratic combination (CQC) method are used for seismic analysis. Result presented by both the SRSS and CQC method is compared with time history response analysis to get the accuracy in the result for adaptability of the method. The natural circular frequencies computed by the three mass matrix corresponding to the first 20 mode. It has been find that the natural frequency computed by him both methods lumped mass and consistent mass method approaches to exact solution if number of beam segments increased. For the maximum response of displacement assuming $2 \%$ damping, the participation factors and the modal cross-correlation coefficient can be computed. In comparison, of displacement the SRSS method greatly underestimates the horizontal displacement in the direction of motion and also the vertical displacement found by the CQC method are underestimated, but the effect of the time history response analysis is more eminent than those of two methods. This analytical calculation of dynamic characteristic is a mathematical relation between the exact methods based on the general resolution of differential equation, natural frequency calculation by using different mass consideration methods. In Eigenvalues of rigid frame bridge is can be computed by a consistent mass method than by the lumped mass method.In this calculation of response spectrum, calculation of the values of participation factors and the modal cross-correlation estimated by same higher modes are larger than those calculated by first few lower modes. In this result the two dimensional rigid frame construction, it is purported that the two methods of combining modal maxima yield good result when compared to the time history response calculations.

Brownjohn et al. [1992] In this paper did a full scale dynamic test of the second Bosporus was performed on a suspension bridge, open in 1989, as part of second peripheral highway around Istanbul. It delivers 8-lane boxed deck is $39.4 \mathrm{M}$ wide, $3 \mathrm{M}$ deep and $1090 \mathrm{M}$ long and suspended by vertical hanger. The foundation is $8 \mathrm{M}$ below, deck level to a height of $110 \mathrm{M}$ above ground floor. The testing of Faith Bridge was the third in a series of ambient vibration surveys. The aim of this trial is to find the natural frequency mode shape and the damping ratio for vertical, lateral, torsional direction and the associated mode in the deck and tower up to a maximum of $2 \mathrm{~Hz}$. The equipment for the experimental setup used is accelerometers and amplified by power supply/conditioner unit, four channel FM tap recorded data, some signal were processed on site in real time utilizing a spectrum analyzer to find the Fourier spectra of the acceleration signals and to compute the amplitude and phases of the signals. For the subject trial. The 28 position was determined for acceleration spectra in this bridge the three direction mode were recorded in vertical modes 1-12 point the node frequency ranges from 0 $6 \mathrm{~Hz}$, but strong response between $2 \mathrm{~Hz}$ and $4 \mathrm{~Hz}$, torsional deck modes at 5 points to capture the mode shape. Lateral deck models had 8 points were the strong response around the. $03 \mathrm{~Hz}$, longitudinal tower modes consist of 13 points, apart from participation in some of the lower vertical deck modes, the strongest modes occur above $1 \mathrm{~Hz}$ and all but three of the measured modes in the ranges 1-2 $\mathrm{Hz}$ corresponds to a deck mode. The measured vertical natural frequencies and modes featuring bearing fixed at one end and free to slither at the other. Vertical modes of the deck are clearly defined while the lateral modes are weak and badly specified. The traffic loading for the bridge was down because of the low traffic at the time of testing

Harik et al. [1997] He study the double-deck through truss brent-spence Bridge for the dynamic behavior. The bridge is come over the Ohio River region New Madrid, Wabash valley or anna seismic zone. Bridge was opened for traffic in 1961 and rehabilitated in 1984-85 for repair of joints, lighting, drainage system but the most important is to add the one additional lane to this bridge. It has four pier and three span in which center span is $253.1 \mathrm{M}$ and other two span is $138.1 \mathrm{M}$. The work on this bridge is divided into the 


\section{International Journal of Science and Research (IJSR) \\ ISSN (Online): 2319-7064}

Index Copernicus Value (2015): 78.96 | Impact Factor (2015): 6.391

two major part first is field test (ambient vibration test) and second is modeling of bridge.

For the ambient vibration test it also divided into the three part to conduct the test.

1) Sensor used for the test:-In this triaxial accelerometer kinemetrics SSA-2 and kinemetrics FBA-23 for the recording of the ground acceleration of $\pm 2 \mathrm{~g}$ and 40 second time window is used.

2) Data acquisition system and analysis:-The sensor are placed at different location and record the data for the analysis, Fast Fourier transform (FFT) is used to generate the spectrum. The acceleration caused by vibration are recorded for the time window of 40 second in all direction at one place and peaks in FFT corresponding to the natural frequency of the structure. Frequency varies with position and peak is not always come at the same value its various with a certain rang. Mode shape is obtain by plotting the ratio of the FFT at each station with appropriate sign versus the base station

3) Test method: - In this test half portion of bridge is selected for testing due to symmetry and 1-13 position on bridge is marked. Chose the base station and fixed it and the other two sensors are moving in different position and simultaneously record the data for the FFT system. System record the all three direction such as longitudinal transvers and vertical direction at a point

Now the second most important half of this study is modeling of bridge. In this analysis modeling based on the finite element model (FEM) such as linear elastic modeling done by using ANSYS software. Model consist of 1536 element with 756 nodes. Modeling of different parts such as superstructure, bearing, substructure for the analysis of dynamic characteristic such as natural frequency, mode shape etc. and model is calibrated by using ambient vibration test result. All the above method in this paper is used for the comparison of natural frequency and finding for the mode shape with ambient vibration test and verified by modeling of bridge on ANSYS this result is used for the seismic analysis.

Wahab and Roeck [1998] In this paper the dynamic testing of pre-stressed concrete bridge is done on three different bridges. The first bridge is situated at the village of Peter and melsbroek built in 1971. It has an over length of $89 \mathrm{M}$, width of $13 \mathrm{M}$ and two traffic lanes the middle span is $38.5 \mathrm{M}$ and two side span are $25.25 \mathrm{M}$. second bridge under consideration is B15 located between the village of peutie and perk. It is a box girder bridged and has three spans with an overall distance of $124.6 \mathrm{M}$. The box girder is $9.4 \mathrm{M}$ wide and has two traffic lanes. An important feature of B15 is that it is a skew-symmetric bridge. Third bridge B13 is located between the village of vilvoorde and melsbrock. The total length of the bridge is $102.37 \mathrm{M}$ divided over the three spans (39.3 M Midspan and $2 \times 31.5 \mathrm{M}$ side span) it carries four traffic lanes and gets in a width of $26 \mathrm{M}$. Likewise the three different excitation type to read the ambient vibration test are artificial means, impact weight, traffic (big truck) and two methods were applied for data analysis are (DDS) datadependent system/ARV model average vector model and (FFT) fast Fourier transform of the reaction and the force function. The finite element modeling is done by using
ANSYS on the 4938 nodes and determine mode shape and damping ratio compare the result of loading and FEM model to give results.

C. C. Chang et al. [2001] Cable stayed bridge, Hong Kong bridge with double decks H-shaped column, upper deck carries six-long two-way highway traffic and lower deck carries two railway tracks plus two emergency highway lanes, having a main brace of $430 \mathrm{~m}$ and 4-span of $80 \mathrm{M}$ and either side of the main bridge. The bridge is located in a typhoon and monsoon area. So it experience serve wind during its service lifetime. It is important to analysis the effect of ambient forces. The dynamic characterizations are analysis by using ambient vibration field test and compare the answer with the finite element modelling method. In field, ambient vibration using equipment are 19accelerometer, 1-anemometer, 24- channel data acquisition system in which out of 19- accelerometer 16 are kinematics, FBA-11 uniaxial, force balance accelerometer, which occur with frequency responses from $\mathrm{DC}$ to $100 \mathrm{~Hz}$ with $66 \mathrm{~dB}$ gain and 3 are the cross bow CXLO1M3, triaxial silicon machined accelerometer with frequency as set with fire DC to $100 \mathrm{hz}$. The FBA-11 accelerometer was used for the deck measurement and the CXLO1M3 accelerometer were used for the deck measurement was applied to evaluate the wind velocities on the bridge deck during the measurement. For the measurement of ambient force the span is divided several sections of $53 \mathrm{~m}$ apart between two adjacent section points. The information received from the field trial were carried utilizing a streamlined ambient vibration analysis procedure, which was prepared for the purpose of placing the dynamic features of long span bridge from the recorded ambient vibration data. The major component of the procedure is centered along the traditional frequency domain methods. The ARMA model of providing an alternative for the determination of damping ratios, for the details on the ripening of the streamlined program can be found in the paper by Chang et al. [1997]. for the second half of the composition is a finite element modeling of bridge which is obtained by the geometry and structural properties estimated from the figure drawing. Cable-stayed bridge exhibit same nonlinear behavior under either static or active loads. Then the free vibration analysis is then conducted based on this static equilibrium position. The three dimensional FE modeling is constructed using linear elastic beam elements for the tower and the deck, truss element for the flexible or rigid links for the connector and the boundary constraints. For the modal analysis, total 32 natural frequency is obtained that range between 0.41 and $3.39 \mathrm{~Hz}$. The example is separated into the following four groups, verticallydominate modes, the lateral-dominate modes, the torsionaldominate modes and the tower -dominate modes. The dynamic features of long span bridge compare the two solutions, the result show reasonable correlation in term of the natural frequency and the mode shape have been carefully matched to the frequency difference range between 0 to $30 \%$

Kung-Chun et al. [2006] Field test using the ambient vibration test on the GI-LU Bridge located in NANTOU county Taiwan. It is modern pre-stressed concrete cable stayed bridge which crosses the Juosheui River in Taiwan, a length of $240 \mathrm{M}$. Two different equipment's are utilized for 


\section{International Journal of Science and Research (IJSR) \\ ISSN (Online): 2319-7064}

Index Copernicus Value (2015): 78.96 | Impact Factor (2015): 6.391

sensing the vibration, MEMS-based wireless sensor system and traditional microcomputer based system were utilized to collect and analysis ambient vibration data. Mode shape was identified for cable and the deck structure within the frequency range of $0-2 \mathrm{~Hz}$ for the field test equipment are VSE-15 velocity detector with a sensitivity factor of 0.25 volts/1 line, 9 wireless sensing units, each with voltage converters and power supply system, one PC-microcomputer with wireless mode to assist as the trigger and recording scheme. There are three different ways to recorder the vibration first recorded the vertical dynamic response of the bridge deck, at 9 different locations; second both cable and deck vibration were measured simultaneously. Third is only at the cable vibration. The wireless sensing unit developed by LYNCH et al. [2000].The max stream X-steam wireless modem operating at $2.4 \mathrm{GHz}$, used for the wireless communication subsystem. A total of 12 sensing units was used simultaneously and directional antenna was used to enhance the signal communication and to extend the range of the sensors in the field. For analysis of ambient vibration data there are several system is applied but the model estimation through correlation function is presented. The stochastic subspace identification method (SSI) as present by Van Overschee and De Moor is a method to classify the stochastic state space model from output only measurement by using robust numerical techniques such as Q-R factorization, singular value decomposition (SVD)and least squares. It is possible to gather at least 12 sensors simultaneously with sampling rate of 100 point per second. It is a full scale cable stayed bridge test for dynamic properties, that identified the mode shape frequencies, damping ratio there are many advances to deal with spatial data and extract mode shapes of the vibration structure such as the frequency domain decomposition method (FDD) for the damping ratio, approximation the first vibration mode of the deck was between $3.5 \%-9.5 \%$ depending the estimation from different location.

You-liang et al. [2007] In his experimental study on ambient vibration for the finite element modeling of the tower and cable, ambient vibration test in conducted. The model is update time to time according to the ambient vibration test. On the basis of updating tower model the dynamic characteristic properly define. It helps to ascertain out the reaction using a theoretical finite element model and actual experimental response. The basic demand for finite element model updating is considered that the structural modeling error and model meshing error to be eliminated in the initial Finite element model. Multilevel model updating method is set forward for Finite element modelling of the bridge tower for long span cable stayed span. It assists in updating model parameter to produce good answers.

Huang et al. [2008] In this paper ambient vibration test and finite element modelling of the main road bridge over a railroad on NO.312 national highway is done. The Shiloh Bridge is situated in a suburban area of the Xinyang city of Henan province total length is 226.57 M designed in 1994 and built in 1996, skew angle of $31^{\circ}$. In this first the theoretical analysis done, then the ambient vibration test is performed and compare the outcome. For theoretical analysis the FE model is founded on the ANSYS software is employed for the molding of the span. In ambient vibration test the equipment used is the INV-306C data acquisition and signal processing system. Condensation between the subject area test and modeling result the error is ranges from $(0.44 \%-8.77 \%)$ for the accuracy in result the model updating in necessary for the following points (1) sensitivity analysis (2) optimization design (3) finite element model updating. Update the model can reflect the dynamic features of the bridge more accurately.

X-H Chen [2014] He study the curved post-tension concrete box-girder bridge which is situated at New Zealand, original Newmarket viaduct bridge constructed in1966, it was first post-tension bridge, at the $21^{\text {th }}$ century daily traffic on this bridge is 160000 vehicles approximately, old viaduct get deteriorate with time and increased traffic so the old viaduct is replaced with the new bridge, work start from 2009 and completed in 2012 for traffic there is two bridge constructed parallel are southbound and northbound. It consist of 12 span length ranging from $38.7 \mathrm{M}$ to $62.65 \mathrm{M}$, so that the total length of the bridge is $690 \mathrm{M}$, it also have two horizontal curved of radius $760 \mathrm{M}$ and $690 \mathrm{M}$ and one vertical curve, supported on 24 column and height of intermediate column ranges from $4.14 \mathrm{M}$ to $21.78 \mathrm{M}$. He study the bridge analytical and experimental approach for check the integrity of structure. His work is divided into four part.

1) Ambient vibration testing: - He performed the ambient vibration test on southbound bridge on November 29, 30 in 2011 under the traffic condition. The sensor used for the recording is two wireless accelerometer X6-1A and X6-2 (www.gcdataconcept.com) is placed on the both side of girder and inside of the deck sensor is placed. There is 188 location are selected inside the bridge girder, for each point there is seven fixed and 45 moving sensor are used and five reference node in which seven sensor are used. Sampling frequency of range of $160 \mathrm{~Hz}$ and after the filter frequency is not much higher because the necessary for multi-span bridge is low.

2) Model identification process and result: - For the data processing MATLAB (Beskhyroun 2011) program is used and the technical used for the written program EFDD and SSI. This two method is used for the estimation of natural frequency and mode shape EFDD (jacobsen et al. 2007) and SSI (Van Overschee and De Moor 1996; Katayama 2008) the basic difference in this two method are in SSI variation of natural frequency quite large than EFDD method.

3) Preliminary FE modelling:- In FE model structure divided into number of element using SAP2000 software, 3D-model of bridge is proposed and pier deck slab all are considered as a soiled element. A mesh of element is prepared and the assigned the material properties to every element, such as stiffness, density, young modules and mass distribution system. Apply the boundary condition to model and calculate the response.

4) Model refining and updating:-In this he fined that the experimental natural frequency is higher than the FE model natural frequency for the first four transverse mode. So the model required the update, experimental vibration lower horizontal vibration modes are underestimated and the stiffness of FM modal is also underestimated. So that the difference in the natural 


\section{International Journal of Science and Research (IJSR) \\ ISSN (Online): 2319-7064}

Index Copernicus Value (2015): 78.96 | Impact Factor (2015): 6.391

frequency caused by the shearing stiffness, numerical methods are develop to minimize the difference (Bedon and Morassi(2014) and Ntotsios et al. 2009) using numerical simulation. Maximum difference are reduced by using material properties and increase young's modulus of deck and pier by $20 \%$.

Now the above discussion the experimental frequency measured upto $8 \mathrm{~Hz}$, two different approaches such SSI and EFDD show the good agreement of mode and natural frequency. When comparing the numerical and experimental result it was seen that there was a large difference between the natural frequency predicted by FE model and ambient vibration test and difference eliminated by refined FE model of the bridge and updated by tuning the boundary condition and experimental measurements.

Shimoi et al.[2014] At a Second European conference on earth quack engineering, they represented a paper on comparative study on the natural frequency of bridge obtained from the two different sensors accelerometer and bolt type piezoelectric cable, which used for the real-time structural health monitoring. Piezoelectric cable is installed at the support of the bridge where large change in stress condition. The AsukaOhashi Bridge used in experimental study is located at Yurihonjo city, japan. It was constructed in 1979, it is a composite section of steel girder and concrete deck slab which are supported on intermediate six piers with seven-span of the total length of $256 \mathrm{M}$. The span connected to abutment and pier is selected for the observational study. It is found that on the basis of obtained predominant frequencies result of the piezoelectric sensor shows good agreement to the accelerometer sensor. It is also used in verification of moving load impact on bridge by using 19 ton truck.

\section{Conclusion}

For the earthquake resistant design of structure, especially like Bridge, which are indeterminate structure are solved by complex quadratic equation to get the dynamic characteristic. Ambient vibration test and finite element modeling are one of the useful methods to get the response. Following conclusion has been extracted from the above review papers presented in this report.

- There are various equipment (sensor) used for the ambient vibration test.

- Ambient vibration test is easily conducted on bridge without any damage to bridge on running services condition.

- Finite element modeling is done through the various software such as SAP2000, ANSYS, etc.

- Various techniques such as Fast Fourier transform, stochastic subspace identification (SSI), peak picking method operational model analysis etc. are the method used for the dynamic response data.

- Through model updating we get more dependable dynamic properties.

- In this we compare two different results come from experimental and analytical method.

- It also helps to find the damage in the structure with respect to time, to get prepared for the retrofitting
- We recorded the data for the different location at the time of testing simultaneously, with the avail of the wireless sensor, having proper range to get the information for different test location.

- In this we also compare the result of the two different mass consideration method for better results of bridge response.

\section{References}

[1] A. Cunha, E. Caetano and R. Delgodo. (2001) "Dynamic Test on Large Cable Stayed Bridge", Journal of bridge Division proc. of ASCE Vol.6 pp.54-62, 2001.

[2] Anthony H. Depiero, Robert K. Paash, and Steven C. Lovejoy. (2002) "Finite ElementModelling of bridge Deck Connection Details", journal of bridge Division Proc. of ASCE, vol.7 pp.229-235, july-August 2002.

[3] B.Li.C.F. Duffield and G.L. Hutchinson. (2008) "Simplified finite element modelling of Multi-Story Building: The use of Equivalent Cubes", Reported in Electronic Journal of Structural Engineering, 2008.

[4] BijayaJaishi and Wei-Xin-Ren. (2005) "Structural Finite element Model Updating using Ambient vibration test result", Journal of Structural Division, proc. of ASCE, pp.617-628, April 2005.

[5] C.C. Chang, T.Y.P. Chang and Q.W. Zhang (2001) "Ambient Vibration of Long-Stayed Bridge". Published in Journal of Bridge Engineering ASCE, pp. 46-53, January-February 2001.

[6] C.A.M de smet, C. Kramer, and G.R. Darbre. (1998) "Ambient vibration test at the dam of Mauvoisin", $16^{\text {th }}$ of IMAC, 1998

[7] Carlos E. Ventura, Jean-Francais, and Robert D.Simpson. (2002) "Effective use of ambient Vibration measurement for modal updating of a 48 story building in Vancouver Canada" International conference on structural dynamic Modelling- testing analysis correlation and Validation Canada, 2002.

[8] De silva, C.W., (2007) "Vibration Monitoring Test and Instrumentation", CRC Press, Taylor \& Francis Group, Boca Raton, 2007.

[9] DavideRaio, FabrizioGara, Alessandro Balducci, and LuiginoDezi. (2014) "Ambient Vibration test on a reinforced concrete school Building before and after the retrofitting works With external steel dissipative tower", $9^{\text {th }}$ International conference on structure dynamics Eurodyn.2014, ISSN: 2311-3020.

[10]Ding You-liang, Li-Ar-qun, Mio Chang-qing, Han Xiao-lin(2007) "Finite Element Modeling of the Tower of Runyang Cable-Stayed Bridge Based on Ambient Vibration Test". Journal of Highway and Transportation Research and Development ASCE, vol. 2, pp.40-47, 2007.

[11]F.E. Udwadia and M.D. Trifunac(1973) "Ambient vibration Test of Full-Scale Structures", 5 $5^{\text {th }}$ World Conference on Earthquake Engineering, Rome, 1973.

[12] Ghada Saudi, Paul Reynolds, Mohammed Zaki and HossanHodhood (2009) "Finite Element Model Tuning of Global Modes of a Grandstand Structure using Ambient vibration testing", Journal of Performance of Constructed Facilities Division Proc ASCE pp.467-479, 2009. 


\section{International Journal of Science and Research (IJSR) ISSN (Online): 2319-7064}

Index Copernicus Value (2015): 78.96 | Impact Factor (2015): 6.391

[13]I.E. Harik, D.L. Allen, R.L. Street, M. Guo, R.C. Graves, J.Harison, M.J. Gawry (1997)"Free and Ambient Vibration of Brent-Spence Bridge". Journal of Structural Engineering ASCE, pp. 1262-1268, September 1997.

[14] Ichiro Konishi and Yoshikazu Yamada (1960) "Earthquake response and earthquake resistant Design of long span suspension bridges", Associations of science documents information, Proceeding of the second world conference on Earthquake engineering Tokyo and Kyoto, Japan, 1960.

[15] J.M.W.Brownjohn, R.T.Seven and A.A. Dumanoglu (1992) "Full-scale Dynamic Testing Of The Second Bosporus Suspension Bridge" Earthquake Engineering Tenth World Conference Balkema Rotterdam, 1992.

[16]J.M.W. Brownjohn, Pin-Qi-Xia, Hong. Young Xia. (2001)"Civil Structure Condition Assessment by FE Model Updating Methodology and Case Studies", Finite Element Analysis and Design Division Elsevier pp.761755,2001 .

[17] James H. Gates and Monte J. Smith (1982)"Result of Ambient Vibration Testing of Bridges", NISEE-PEERUniversity of California, Berkeley, 1982.

[18] James Mark WillamBrownjohn, PilateMoyo, Piotr Omenzetter and Young Lu (2003) "Assessment of Highway Bridge Upgrading by Dynamic Testing and Finite-Element Model Updating", bridge journal ASCE pp.162-172, 2003.

[19] Jaturong. Sa-Nguanmanasak, Taweep Chaisomphob and Eiki Yamaguchi. (2010) "Improvement on design Analysis of Composite Steel-Concrete Bridge using Elaborate Finite Element Method", SangklanakarinJ.Si Technical 32(3) pp.289-297, 2010.

[20] Jeong-Tae Kim and Norris Stubbs. (2003) "NonDestructive crack detection algorithm for Full-Scale bridges", Journal of bridge engineering ASCE vol.129 (10) pp. 1358-1366, 2003.

[21] Juan C. Carvajal, Carlos E Ventura, and Hugon Juarez. (2009) "Damage assessment of caisson Foundations in a port facility using ambient Vibration measurement", $16^{\text {th }}$ of IMAC Orlando Florida USA, 2009.

[22] Kai H Hsieh, Marvin W. Halling, and Paul J. Barr (2005) "Overview of System Identification and case Studies using Vibration Techniques" Journal Structure Congress ASCE, pp. 1-12, 2005

[23] Kung-Chun Lu, Yang Wang, J.P. Lynch, C.H. Loh, Yen Chen, P.Y.Lin, and Z.K. Lee (2006) "Ambient vibration study of the Gi-Lu Cable-Stay Bridge: Application of Wireless Sensing Units", Smart Structures and Materials 2006 -Sensors and Smart Structures Technologies for Civil, Mechanical, and Aerospace Systems - San Diego, CA, United States, 2006.

[24] Lingmi Zhang, Yukio Tamura, Akihiko yoshida, Kangpyo Cho. (2002) "Ambient vibration Testing and modal identification of an official Building" $20^{\text {th }}$ international modal analysis Conference (IMAC) Los Angeles USA, 2002.

[25] M.M. AdbelWahab and G.DeRoeck(1998) "Dynamic Testing of Prestressed Concrete Bridge and Numerical Verification" Journal of Bridge Engineering ASCE, pp. 159-169, November 1998.

[26] M.Q. Feng, J-M. Kim, and H. Xue. (1998) "Identification of dynamic system using ambient
Vibration measurement", The ASME journal of Applied mechanics vol 65, December1998.

[27] Marvin W. Halling, Ikhsan Muhammad and Kevin C. Womack. (2001) "Dynamic Field Test Condition Assessment of Bridge Bent" Journal Of Structural Engineering ASCE vol.127 (2) Pp.161-173, 2001.

[28] Marc O. Eberhard, M. Lee Marsh. (1997) "Lateral-Load Response of a Reinforced Concrete Bent", journal of Bridge Engineering ASCE vol. 123(1) pp.461-468, 1997.

[29] Minshui Huang, WenzengGuo, Hang Ping Zhu,Lin Li. (2008) "Dynamic Test and Finite Element Model Updating of Bridge Structure Based on Ambient Vibration", Front. Archit. Civ. Eng. China 2(2) pp.139$144,2008$.

[30] NobuhiroShimoi, MasshiroSaijo, Carlos Cuadra, and HirokazuMadokoro(2014) "Comparison of Natural Frequencies of Vibration for a Bridge Obtained from Measurement with Accelerometers and Piezoelectric Cable Sensor" Second European Conference on Earthquake Engineering and Seismology, Istanbul, pp. 25-29, August 2014.

[31] Olusegun S. Salawu and clive Williams. (1995) "Bridge Assessment using Forced-Vibration Testing”, journal of structural engineering ASCE vol.121 (2). Pp.161-173, 1995.

[32] Sakai.J., Kobayashi. H, and Unjoh.S (2007) "Real-Time Earthquake Damage detection System for Bridge Structure", proc. $23^{\text {rd }}$ US-Japan Bridge Engineeringworkshop, Public Works Research Institute, 2007.

[33] ToashiroHayashikawa, Takakichi Kaneko, Yoshtika Matsui and Koichi Yoshida (1988) "Dynamic Response Analysis of a Five Span Continuous Rigid- Frame Bridge with V-Shaped Legs". Report Proceedings of Ninth World Conference on Earthquake Engineering, Tokyo-Kyoto Japan, pp. 513-517, 1988.

[34] V.ZanjuaniZadesh and A. Patnaik. (2014) "Finite element modelling of the Dynamic Response of a composite Reinforced Concrete Bridge for Structure Health Monitoring", International Journal of Advance Structural Division proc, Springer, vol 6, issue 2, ISSN: 2008-3556, 2014.

[35] Wei-Xin Ren, Tong Zhao and Issan E. Hairk (2004) "Experimental and Analytical Modal Analysis of Steel Arch Bridge", Journal of Structural Engineering ASCE, vol.131(4), pp. 1022, 2004.

[36] Wilson, J.S, (2005), "Sensor Technology Handbook" Newnes, Burlington, MA, 2005.

[37]X-H. chen, P.Omenzetter, and S.Bekhyroun (2014) "Ambient Vibration based Evaluation Of a Curved Posttension Concrete Box-Girder Bridge" New Zealand society for Earthquake Engineering (NZSEE) Annual Technical Conference, 2014.

[38] $8^{\text {th }}$ proc. world conference on Earthquake Engineering (1992), book of various paper in this volume were set individually by Tyoists under the suoervision of each auther concerned. Sponsored by international association for earthquake engineering. Published A.A.Balkema/ Rotterdam, 1992. 